\title{
THE DIAGNOSTIC VALUE OF LYMPH NODE ASPIRATION BIOPSY
}

\author{
By P. F. Lucas, M.D., M.R.C.P. \\ From St. Bartholomew's Hospital, London
}

Excision of a lymph node often requires general anaesthesia and admission to hospital which may entail considerable delay in diagnosis and treatment-a delay which is prolonged by the fixation, cutting and staining of sections. Aspiration biopsy is done under local analgesia so that admission to hospital is unnecessary and much time and expense saved. Against these advantages must be placed the difficulty of interpretation caused by the paucity of material obtained which may not be fully representative of the node, and by the inability to assess the architecture of the node and the occasional failure to obtain tissue. These drawbacks are diminished by the ease with which further aspirations can be carried out and by the general distribution of abnormalities of cytology by the time a node is large enough to puncture. A more serious danger is dissemination of disease. Manipulation and aspiration of animal tumours has led to dissemination in some investigations (Tizzer, 1913; Young et al., 1950) but not in others (McLean and Sugiura, I937). The method has been strongly condemned on this ground (British Medical Fournal, 1951; Craver, 1940) and on the ground of difficulty of assessment (Robb-Smith, 1947; Symmers, I951). The danger of spreading disease is difficult to assess but there is no account of fungation or local spread in the literature. The only complications recorded are six cases of haemorrhage which were easily controlled (Estrada, 1936; Cathie, 1938; Christiansen, 1942; Hermitte and Ellis, 1948), one of infection (Strunge, 1944) and one of pneumothorax (Stanel, 1939). The method has been little used in this country and this paper is an attempt to assess its value in diagnosis.

\section{Material and Methods}

One hundred consecutive patients with lymphadenopathy have been examined by aspiration biopsy. The final diagnosis was confirmed histologically in the majority of cases.

Aspiration is carried out under local analgesia with a $20 \mathrm{cc}$. syringe through 18 gauge needles.
The needles are fitted with stylets so that skin blood and tissue fluid do not enter them. Tho capsule is pierced only once and no attempt made to massage the node or to break up its subs stance with the needle. The few drops of tissus obtained are pushed on to grease-free slidespo smeared by pressure with another slide and staine by the May-Grunwald-Giemsa technique. A search is made for abnormal cells under the $1 / 6$ in objective of the microscope and the oil immersio $\vec{g}$ lens used to confirm detail.

The diagnosis of many of these cases was knowio before aspiration was carried out. In order to test the value of the method and to rule out clingcad bias, one smear from each aspiration was numbered and arranged at random by an assistant. Egob smear was examined for an arbitrary period of I 5 minutes as the time which a practising path ologist might be able to give. At the end of this time a diagnosis or an alternative diagnosis was made or the smear was put aside with no diagnosis.

\section{Results}

The table shows that a diagnosis was made in cases; 49 of these are correct. If ' inflammatiors and 'neoplasm' are accepted as diagnoses, the only error is that a diagnosis of reticulosarcoma wh made in a patient with monocytic leucosis. In the other seven cases the diagnosis of the type of is flammation or neoplasm was uncertain or wrong.

There were no complications of puncture butt from nine patients no tissue was aspirated. Sev of these had Hodgkin's disease and one eaci tuberculous and non-specific lymphadenitis. Thr nodes were small and hard and were not penes trated, four were so dense that nothing could aspirated; the other two patients had Hodgkings disease with large masses of small nodes none of which could be fixed and from which there was yield even after a second attempt. Morrison $\AA_{t} t$ al. (1952) failed to obtain tissue from 12 of $10 \mathrm{y}$ nodes. There is general agreement that the method fails most often in Hodgkin's disease. 


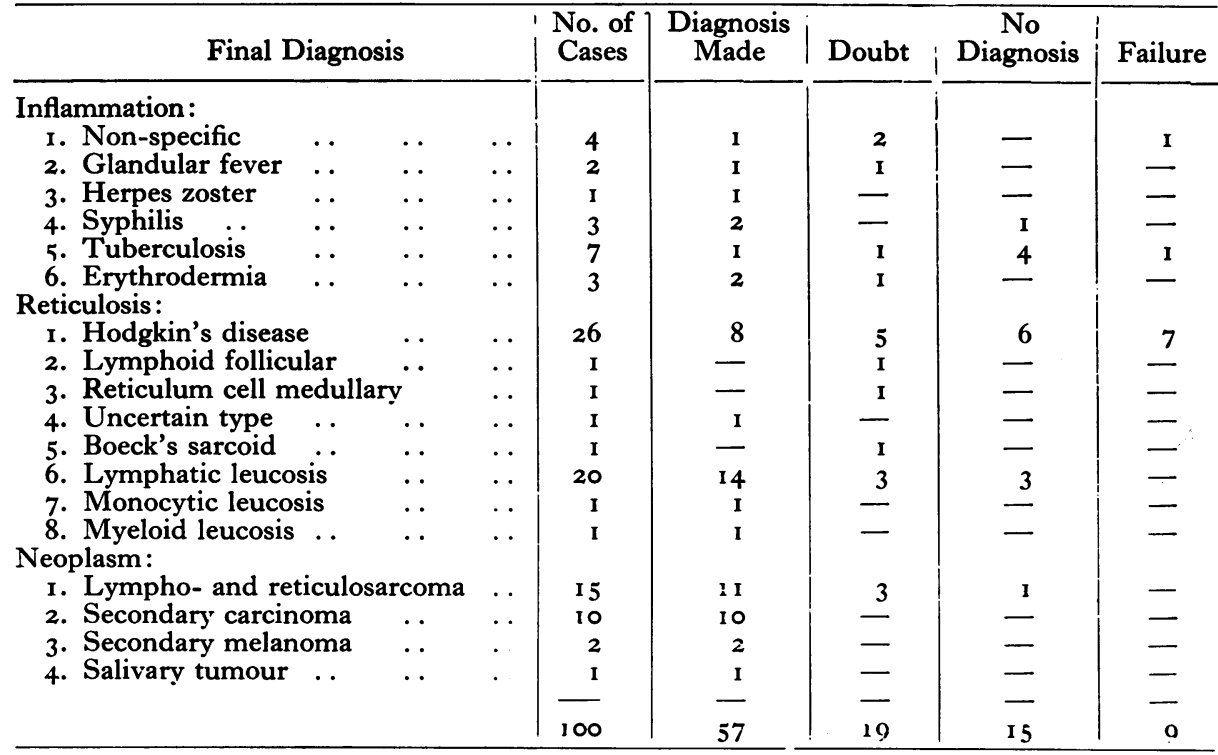

Necrotic tissue was aspirated from five cases and a diagnosis could be made in only one of these.

Analysis on the basis of the final diagnoses shows:

Inflammation. The criterion for the diagnosis is excess of primitive cells at the expense of lymphocytes. Monocytosis suggests glandular fever, plasmocytosis syphilis, histiocytosis erythrodermia. Monocytosis with Langhans' cells suggests tuberculosis. The diagnosis was confirmed histologically in all cases except those of glandular fever, syphilis and herpes zoster; these were confirmed by other investigations.

Of the 18 cases in this group a diagnosis of inflammation of correct type was made in only sixtwo cases each of syphilis and erythrodermia, one each of tuberculosis and glandular fever. Two others were correctly diagnosed inflammatory but were thought to be glandular fever, the final diagnoses being non-specific inflammation and herpes zoster. Of the remaining ro cases, in five there was doubt between inflammation and other disorders and in five no diagnosis was made.

Reticulosis (Plates I-3). The criteria for the diagnosis of Hodgkin's disease are the presence of pre-Sternberg cells, some of which must be greater than 30 microns in diameter, or Sternberg cells, together with an excess of monocytes, plasma cells or polymorphs. For the diagnosis of lymphatic leucosis, 99 per cent. of the cells must be lymphocytes, some of which must contain nucleoli in nuclei of adult type. The diagnosis was confirmed histologically in all the reticuloses except one and by blood and marrow examination in the leucoses.
Of 45 cases in this group a correct diagnosis was made in 24-Hodgkin's disease, eight; lymphatic leucosis, I4; myeloid leucosis, one; a diagnosis from smears of 'reticulosis of uncertain type' is accepted as correct in one patient who has had progressive lymphadenopathy for three years with constitutional deterioration, although reports of non-specific changes only were made on two sur-? gical biopsies. A case of monocytic leucosis was diagnosed reticulosarcoma. Of the remaining 20 cases, one histologically atypical case of Hodgkin's disease was diagnosed 'reticulosis of uncertain type,' in ten there was doubt between reticulosis and inflammation and in nine no diagnosis was made.

Neoplasm (Plates 4 and 5). The criterion for the diagnosis is that 80 per cent. of the cells must be of the same type but show differences in their structure and contain large, dark nuclei some of which must contain nucleoli. The presence of cells adherent to one another suggests carcinoma, very large nucleoli suggest reticulosarcoma. Otherwise distinction depends upon the detailed morphology of the cells. The diagnosis was confirmed histologically in every case except two.

Of 28 cases in this group a diagnosis of neoplasm of correct type was made in 19-lympho- and reticulosarcoma, ten; secondary carcinoma, six; melanoma, two; salivary tumour, one. Five other cases were correctly diagnosed malignant but the type of malignancy was wrong. Of the four cases remaining there was doubt between lymphosarcoma and lymphatic leucosis in two and between reticulosarcoma and an unusually cellular case of Hodgkin's disease in one; necrotic tissue was 


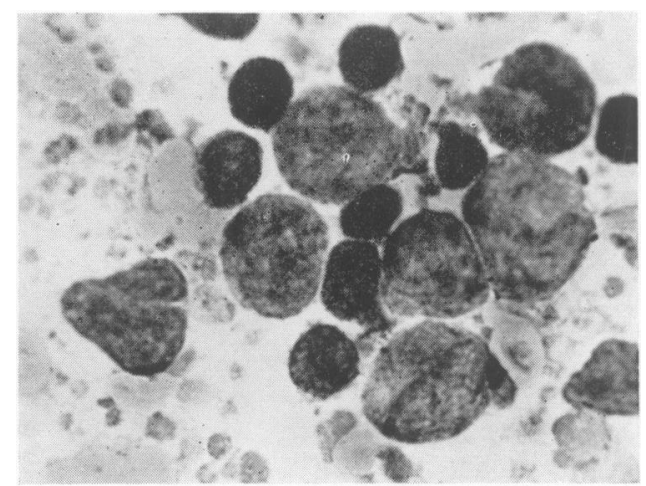

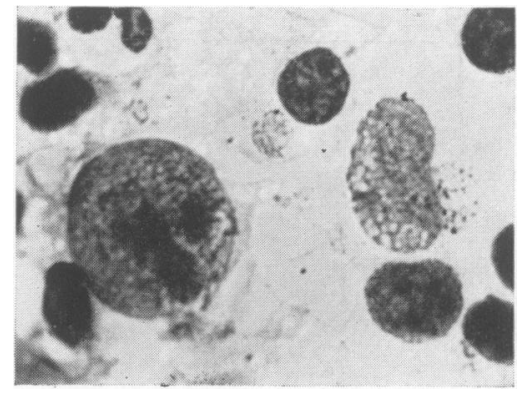

Plate 2.

Plate I.

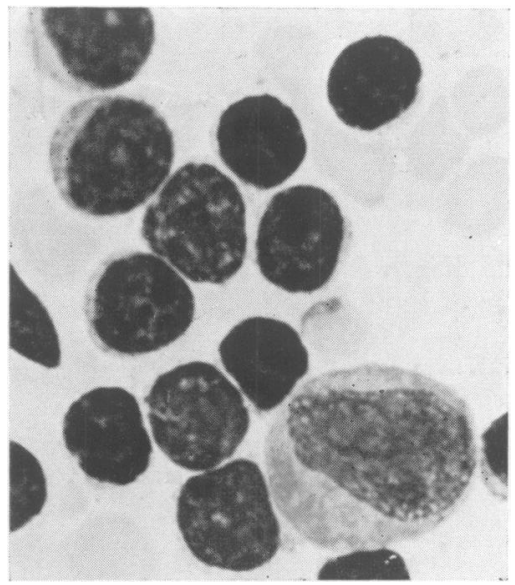

Plate 3.

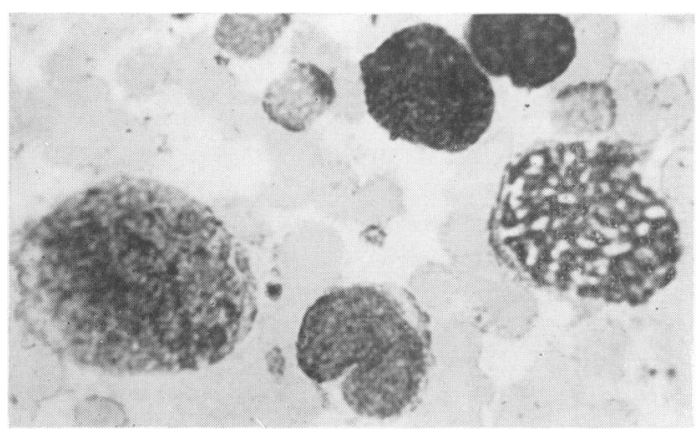

Plate 4.

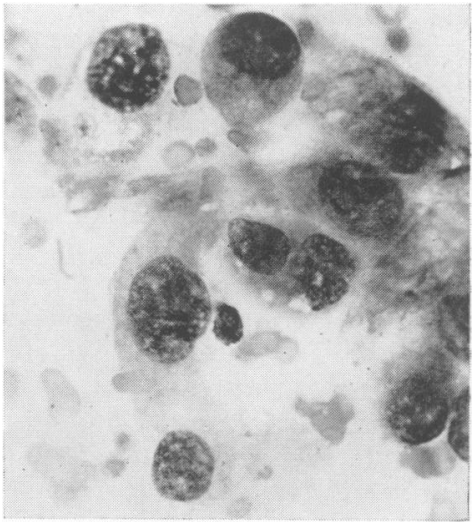

Plate 5. 
aspirated from the fourth case. . A wedge biopsy from one correctly diagnosed carcinoma shows non-specific changes only, but the diagnosis of carcinoma was confirmed at autopsy.

\section{Discussion}

The literature contains little critical assessment of lymph node aspiration biopsy. The impression given is that the value of the method has been greatly exaggerated, although the few figures available of cases in which the diagnosis was confirmed $\cdots$ are less extravagant in their claims. Khanolkar and Sharpune (1944) examined 505 nodes and diagnosed 47 inflammatory lesions and 336 neoplasms but there is little information on the means of confirmation. Other figures show a diagnosis in 21 of 25 nodes (Forkner, 1927), 18 of 32 nodes (Cathie, 1938) and $2 / 3$ of 157 nodes (Blinkenberg, 1938). It is probable that more diagnoses would have been made in this series, especially in Hodgkin's disease, if more time had been spent in examination of smears, and particularly if more than one smear had been examined and more than one node punctured.

A search for abnormal cells is the most important step in diagnosis. If 80 per cent. of cells are abnormal and are of the same type the diagnosis lies between neoplasm and leucosis. The only exception is the rare case of tuberculosis in which as many as 80 per cent. epithelioid cells are present (Leitner, 1940); Langhans' cells are usually seen in such cases. Distinction of the type of neoplasm is often impossible but may be of little importance. Strunge (1944) made the diagnosis in 30 of 35 secondary carcinomata and Morrison et al. (1952) in all of seven carcinomata and 80 per cent. of 12 sarcomata. The method may be valuable in diagnosis of aleukaemic leucosis, as in two cases in this series. The presence of small numbers of abnormal cells suggests Hodgkin's disease, tuberculosis or sarcoid; the latter two cannot be distinguished unless tubercle bacilli are seen. The literature contains very variable reports of the percentage of cases of Hodgkin's disease which can be dfagnosed by aspiration biopsy from 31 of 32 cases (Stuyt, 1947) to 7 of 32 cases (Tèmpka and Kubiczek, I948). In tuberculosis figures vary from 13 of 16 cases (Hermansky, 1949) to 3 of 29 cases (Strunge, 1944). Equally variable figures are given for other types of inflammation. This investigation suggests that a confidant diagnosis of inflammation can rarely be made from smears. Analysis of the doubtful diagnoses shows them to be of no value to the clinician so if a diagnosis cannot be made a node should be excised for histology.

It is well to stress that necrotic tissue may be aspirated from malignant nodes. Of five necrotic aspirates in this series, three are tuberculous, one a reticulosarcoma and one a carcinoma; recognizable malignant cells were seen in the latter.

The accuracy of the method should be assessed on the number of errors rather than on the number of diagnoses made. The method can then be used as a means of screening patients with lymphadenopathy particularly if neoplasm is suspected. If a diagnosis can be made the patient has been saved a much more time-consuming, expensive and unpleasant operation, often necessitating admission to hospital. If it fails or if there is doubt, only the pathologist's time has been lost and a.node can be excised. The smear and section methods can then be considered as complimentary to one another. Alternatively, especially perhaps in Hodgkin's disease in which it may be possible to make a diagnosis from smears at an early stage of the disease, imprints can be made from excised nodes, examination of which may assist diagnosis if histology is uncertain.

\section{Summary}

The results are described of aspiration biopsy of I00 consecutive patients with lymphadenopathy. One smear from each patient was examined for I5 minutes without clinical or pathological information. A diagnosis was made in 57 cases; 49 of these are correct and a further seven were correctly diagnosed inflammation, reticulosis or neoplasm, but the exact type of lesion was wrong. A diagnosis of reticulosarcoma was made in the last patient who had monocytic leucosis. No tissue was aspirated from nine patients and in the remainder there was doubt of the diagnosis or none could be made. The value of the method is discussed and the conclusion reached that if the criteria for diagnosis are strict, accurate diagnoses can be made and the method can be used to screen patients with lymphadenopathy, excision of a node being necessary in case of doubt.

This work formed part of a thesis for the degree of M.D.(Cantab.) and the figures were given in a paper read to the Congress of the European Society of Haematology in 1953. I should like to thank Dr. Bodley Scott for his advice during its preparation and the physicians and surgeons at St. Bartholomew's, Bethnal Green and the Brook Hospitals for allowing me to examine patients under their care. The photomicrographs were taken by Mr. E. V. Willmott.

\section{BIBLIOGRAPHY}

BLINKENBERG, P. A. (1938), Nord. med. Tidskr., 16, 1343. British Medical fournal (195 I), Leading article, if, 344.

CATHIE, I. A. B. (1938), Brit. F. Surg., 26, 324.

CHRISTIANSEN, H. (1942), Acta Radiol., 23, 147.

Continued next page 


\section{PENICILLIN BY MOUTH}

This booklet issued by John Wyeth \& Brothers Ltd. discusses the indications for oral penicillin (Penidural). It also gives a detailed dosage scheme which will be of use to all doctors prescribing oral penicillin. Oral penicillin has a wider range of uses than many realize.

\section{'PHENSEDYL'}

Pharmaceutical Specialities (May \& Baker) Ltd. announce the introduction of 'Phensedyl' brand promethazine cough linctus which contains promethazine hydrochloride in association with codeine phosphate and ephedrine hydrochloride in a pleasantly-flavoured syrup.

The central sedative and local analgesic effects of promethazine combined with the anti-tussive effects of codeine phospate are useful in soothing refractory coughs. In coughs of allergic origin the antihistamine properties of promethazine are most effective. The bronchodilator action of ephedrine is of value in the relief of bronchospasm in bronchitis, asthmatic coughs and whooping cough. In whooping cough the anti-emetic action of promethazine combined with the useful actions of the other constituents make this linctus particularly valuable.

Supplies: bottles of $4 \mathrm{fl}$. oz.

and bottles of 40 .fl. oz.

\section{NEW DRUG FOR THE TREATMENT OE- LEUKAEMIA}

A new cytostatic agent, discovered in the labottories of The Wellcome Foundation Ltd., is now available from Burroughs Wellcome \& Co., unfer the brand name 'Puri-nethol.' Consisting cof scored compressed products containing $50 \mathrm{mgm}$. $\mathrm{C}_{\mathrm{S}} \mathrm{f}$ 6-Mercaptopurine and issued in bottles of 'Puri-nethol' has been shown to provide tebiporary remission, either partial or complete, in acute leukaemia, particularly in children. Simiłar results may be produced in chronic myelogenous leukaemia. The use of 'Puri-nethol' is recommended only where adequate facilities for haengistological control are available. Further information can be obtained on request to Burroughs Welleome

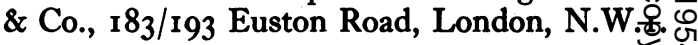

Scorbital tablets each contain phenobarbito $16 \mathrm{mg}$. (1 grain) and ascorbic acid $100 \mathrm{mg}$.

The combination of ascorbic acid with phenobarbitone in Scorbital provides a means क्of diminishing untoward reactions to phenobarbitone; in particular it provides a means of avoiding the ' hang-over' effects so often experienced with phenobarbitone alone.

The normal dose of Scorbital is two to four tablets daily, giving doses of $\frac{1}{2}$ to 1 grain of pheßobarbitone. If necessary, a maximum of eight tablets may be ordered to be taken in 24 hours, giving a full dose of $128 \mathrm{mg}$. (approx. 2 grains) of phenobarbitone. British Drug Houses Ltd.

Bibliography continued from previous page-P. F. Lucas, M.D., M.R.C.P.

CRAVER, L. F. (1940), 'Treatment of Cancer and Allied Diseases,' New York, Vol. 3, p. 2487.

ESTRADA*, A. (1936), Compt. Rend. Soc. Biol., 123, 624.

FORKNER, C. E. (1927), Arch. intern. Med., 40, 647.

HERMANSKY, F. (1949), Casop. lék. ces., 88, 1362.

HERMITTE, L. C. D., and ELLIS, F. (1948), 'British Surgical Practice,' London, vol. 4, p. 297.

KHANOLKAR, V. R., and SHARPUNE, V. V. (1944), Indian Physician, III, 193.

LEITNER, S. J. (1940), Acta med. Scand., 105, 558.

MCLEAN, K., and SUGIURA, K. (1937), \%. Lab. Clin. Med., 22, 1254 :

MORRISON, M., SAMWICK, A. A., RUBBINSTEIN, J., STICH, M., and LOEWE, L. (1952), Amer. Y.' Clin. Path., 22, 255.
ROBB-SMITH, A. H. T. (1947), 'Recent Advances in Clinica Pathology,' Ist edition, London, p. 350 .

STAHEL, R. (1939), 'Diagnostische Drusenpunktion,' Leipzi

STRUNGE, T. (1944), 'La Ponction des Ganglions Lymphatiques,' Copenhagen.

STUYT, L: B. J. (1944), 'De Beteekenis van de Lymphkł punctie voor de Diagnostik van perifere Lymphklierzwellingen, Amsterdam.

SYMMERS, W. ST. C. (1951), Brit. F. Radiol., 24, 469.

TEMPKA, C., and KUBICZEK, M. (1948), Acta Med Scond I3I, 434.

TIZZER, E. E. (1913), F. med. Res., 28, 309.

YOUNG, J. S., LUMSDEN, C. E., and STALKER, A. L. (1 F. Path. Bact., 62, 313.

$$
\text { Ter- }
$$

